\title{
Secretion of neuron-specific enolase, prolactin, growth hormone, luteinising hormone and follicle stimulating hormone by "functionless" and endocrine-active pituitary tumours in vitro
}

\author{
NF LAWTON, AJ EVANS,* JD PICKARD $\dagger$, S PERRY, $\dagger$ B DAVIES \\ From the Wessex Neurological Centre and Departments of Chemical Pathology, ${ }^{*}$ Surgery $\dagger$ and \\ Neuropathology, $\ddagger$ Southampton University Hospitals, Southampton, UK
}

SUMMARY Secretion of the neuroendocrine marker neuron-specific enolase by 24 pituitary tumours was measured in maintenance tissue culture. Eleven endocrine-active and 13 "functionless" tumours were defined by measurement of prolactin, growth hormone, luteinising hormone (LH) and follicle stimulating hormone (FSH) secretion rates in vitro and the corresponding plasma hormone levels. Measurement of prolactin secretion provided a clear distinction between true prolactinomas and "functionless" tumours causing hyperprolactinaemia by stalk compression (pseudoprolactinomas). A previous report of LH and/or FSH secretion by the majority of "functionless" tumours was confirmed, but plasma levels of LH and FSH were usually normal. It is argued that LH and FSH are not the major hormones secreted by "functionless" tumours. A high production rate of neuronspecific enolase appears to be characteristic of the cell type from which most "functionless" tumours derive.

Endocrine-active pituitary tumours secrete known hormones in excess, whereas "functionless" tumours are endocrinologically silent. Secretion by "functionless" tumours is, however, predictable because electron microscopy shows the presence of cytoplasmic secretory granules similar to granules containing known hormones in endocrine-active tumours. ${ }^{1}$ Although the putative hormone secreted by "functionless" tumours is unknown the association of a tumour marker might throw further light on the cell type from which these tumours arise.

Neuron-specific enolase (NSE) is one candidate for such a biochemical marker. As its name implies, NSE is the $\gamma \gamma$ isomer of a glycolytic enzyme present in neurons and their axons, whilst glial cells contain the $\alpha \alpha$ isomer. ${ }^{2}$ Recent studies have shown that NSE is not confined to neurons and is widely distributed in neuroendocrine tissues including the APUD (amine precursor uptake and decarboxylation) cells of the gut, ${ }^{3}$ pancreas, ${ }^{34}$ thyroid, ${ }^{4}$ lung ${ }^{5}$ and adrenal glands. ${ }^{4}$ NSE is therefore a cell marker for the diffuse

Address for reprint requests: NF Lawton, Wessex Neurological Centre, Southampton General Hospital, Southampton SO9 4XY, UK.

Received 18 May 1985 and in revised form 8 August 1985. Accepted 25 August 1985 neuroendocrine system ${ }^{4}$ and is produced by a variety of neuroendocrine tumours. ${ }^{6}$

Marangos $\mathrm{et}^{\mathrm{al}} \mathrm{l}^{7}$ reported the presence of NSE in the normal anterior pituitary of man and monkey but did not comment on its distribution according to cell type. Van Noorden et $a l^{8}$ subsequently showed by immuno-cytochemical staining that NSE is present in all the major hormone producing cells of the normal rat and human pituitary and in tumour cells of adenomas producing growth hormone $(\mathrm{GH})$, prolactin or ACTH. In the same study NSE was demonstrated in the cells of 10 "functionless" human adenomas. These findings were qualitative and it was not possible to predict the production rate of NSE by different cell types. Quantitative studies of NSE production by pituitary tumours have been confined to measurements in CSF. Royds et $a l^{9}$ found high CSF concentrations of enolase in nine of 13 patients with pituitary adenomas but subsequently showed that non-neuronal enolase was more frequently increased than NSE. ${ }^{10}$ The tumour type in patients with high CSF enolase levels was not reported.

We have investigated the production rate of NSE by pituitary tumours of a particular cell type by assaying NSE in the supernatant from maintenance tissue cultures of 24 adenomas. Eleven endocrine active tumours secreting growth hormone (GH) 
and/or prolactin and 13 "functionless" tumours were defined by plasma hormone levels in conjunction with measurements of hormone secretion rate in vitro.

The prolactin secretion rate was measured in every case in order to distinguish true prolactinomas from "functionless" tumours associated with hyperprolactinaemia, and the GH secretion rate to exclude contamination of tumour tissue by normal pituitary. The 13 tumours ultimately classified as "functionless" were chromophobe adenomas which failed to secrete prolactin or growth hormone in vitro despite the frequent finding of modest hyperprolactinaemia in vivo.

Luteinising hormone $(\mathrm{LH})$ and follicle stimulating hormone (FSH) secretion was measured in this study because of conflicting evidence for the frequency with which "functionless" tumours secrete gonadotrophins. FSH and/or LH has been detected by immunoperoxidase staining in only $3.5 \%$ of pituitary adenomas in two large series. ${ }^{11}{ }^{12}$ Mashiter et al, ${ }^{13}$ however, reported FSH and LH secretion by nine of ten apparently functionless tumours in tissue culture and suggested that gonadotrophin secretion by chromophobe tumours is more common than previously supposed.

\section{Patients}

The 24 patients in this study underwent transsphenoidal hypophysectomy for a histologically proven pituitary ade- noma. Great care was taken at operation to distinguish adenoma from normal pituitary tissue. In patients with visual loss, removal of the adenoma and its suprasellar extension was as complete as possible with descent of the ballooned diaphragma sellae into the fossa. The compressed normal pituitary gland was not removed intentionally if it was clearly separate from adenoma. In patients with intrasellar adenomas a selective but microscopically complete removal of the adenoma was performed together with a thin cuff of adjacent normal pituitary gland. The table shows the age, sex, clinical presentation, preoperative plasma hormone levels and the tumour type in each case. Three of the five patients with prolactinomas presented with chiasmal compression only, and the two patients with ammenorrhoea and infertility had intrasellar tumours. The diagnosis of acromegaly in six patients was confirmed by failure of plasma $\mathrm{GH}$ to suppress below $2 \mathrm{mU} / \mathrm{l}$ during a standard oral glucose tolerance test. Two patients with acromegaly also had hyperprolactinaemia and are shown as mixed tumours. Twelve patients with "functionless" tumours who presented with chiasmal compression had no manifest endocrine disturbance. One patient in this category (Patient 24) had long standing hypogonadism, a eunuchoid habitus and a plasma testosterone of $1.1 \mathrm{nM} / 1$ (normal 10-30 nM/1). A pituitary tumour was diagnosed on routine skull radiography after a minor head injury and the CT scan showed a small suprasellar extension. Injection of gonadotrophin releasing hormone $100 \mathrm{ug}$ IV in this patient produced an LH rise from 4.9 to a maximum of $18.5 \mathrm{IU} / \mathrm{l}$ at 60 minutes and an FSH rise from $22 \cdot 7$ to $>40 \mathrm{IU} / 1$ at 20 and 60 minutes. No patient in this series had Cushing's syndrome.

Table Clinical details and pre-operative plasma hormone levels in 24 patients with pituitary tumours

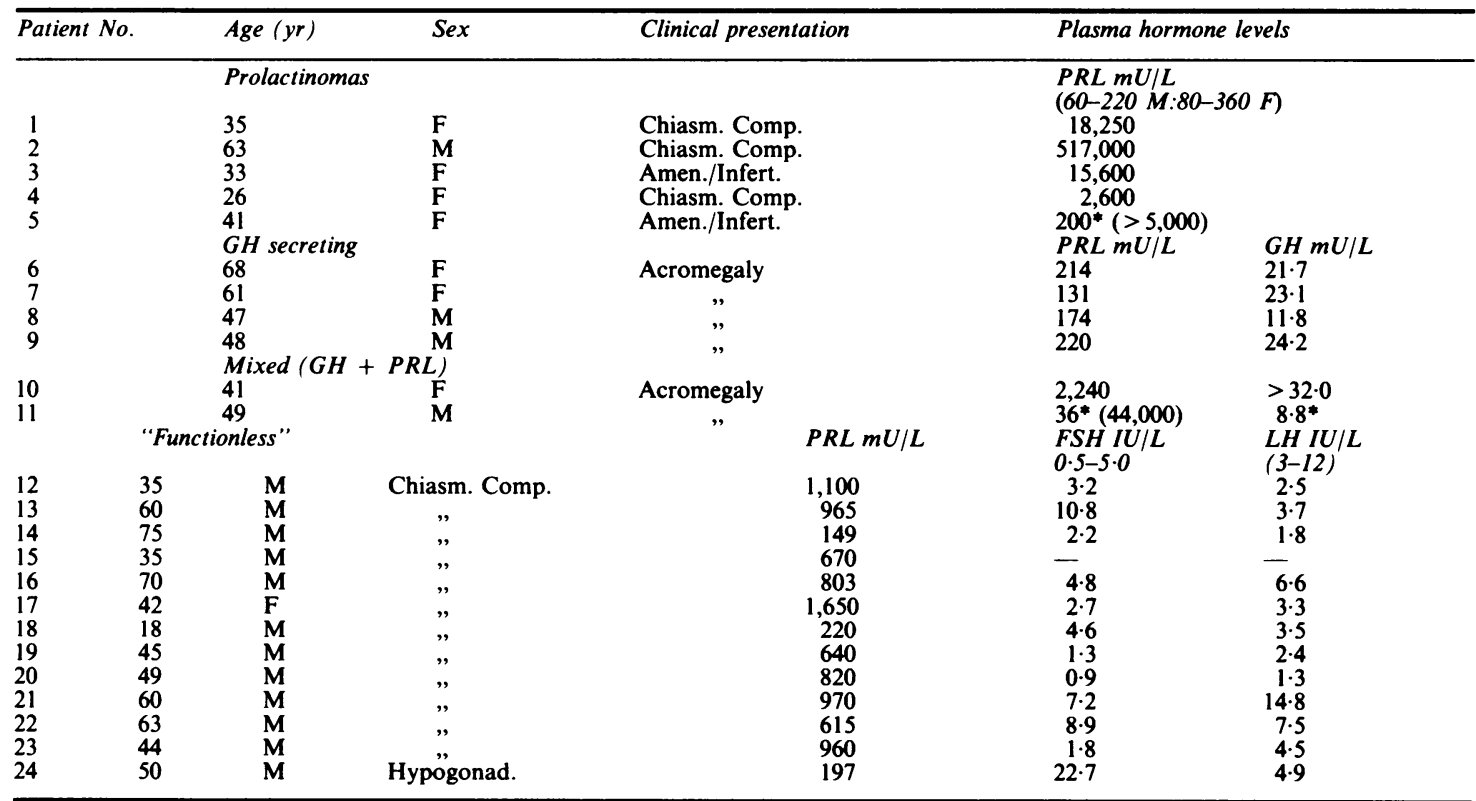

Normal values are shown in brackets. GH levels represent the mean value during an oral glucose tolerance test. Starred values were obtained during treatment with bromocriptine, pretreatment values in brackets. 


\section{Methods}

For maintenance tissue culture fragments of pituitary tumour were washed in normal saline and divided into explants 1-2 mm in diameter within 20 minutes of surgical removal. Two to eight explants of each tumour were placed in $4.0 \mathrm{ml}$ Eagle's Minimum Essential Medium with Earle's salts and added penicillin $1000 \mathrm{U} / \mathrm{ml}$, streptomycin $100 \mathrm{U} / \mathrm{ml}$ and glutamine $2 \mathrm{mM} / 1$. After incubation for 24 hours at $37^{\circ} \mathrm{C}$ the supernatant was collected and stored at $-20^{\circ} \mathrm{C}$ for hormone and NSE assay. The explants were weighed and secretion rates calculated in units $/ \mathrm{mg} / 24$ hours.

GH and prolactin were assayed as previously described, ${ }^{14}$ LH and FSH were measured by radioimmunoassay using LH 68/40 and FSH IRP 78/549 as standards. The LH antiserum was $F 87 / 2$ and showed the following cross-reactivity with other glycoproteins and their subunits calculated on a mass basis at $50 \%$ inhibition ( $\mathrm{LH}=100)$ : FSH $0 \cdot 8$, TSH $2 \cdot 3$, HCG 9.7, $\beta$ LH 15.8, $\beta$ FSH 0.3, $\beta$ TSH 0.4, $\beta$ HCG 15.0, $\alpha$ HCG $<0.1$. The FSH antiserum was M93/2 and crossreactivity on the same basis $(\mathrm{FSH}=100)$ : TSH $0 \cdot 2, \beta \mathrm{FSH}$ 0.8 , LH, HCG, $\beta$ LH, $\beta$ TSH, $\beta$ HCG and $\alpha$ HCG $<0.1$. LH and FSH for iodination were prepared by Professor W Butt.

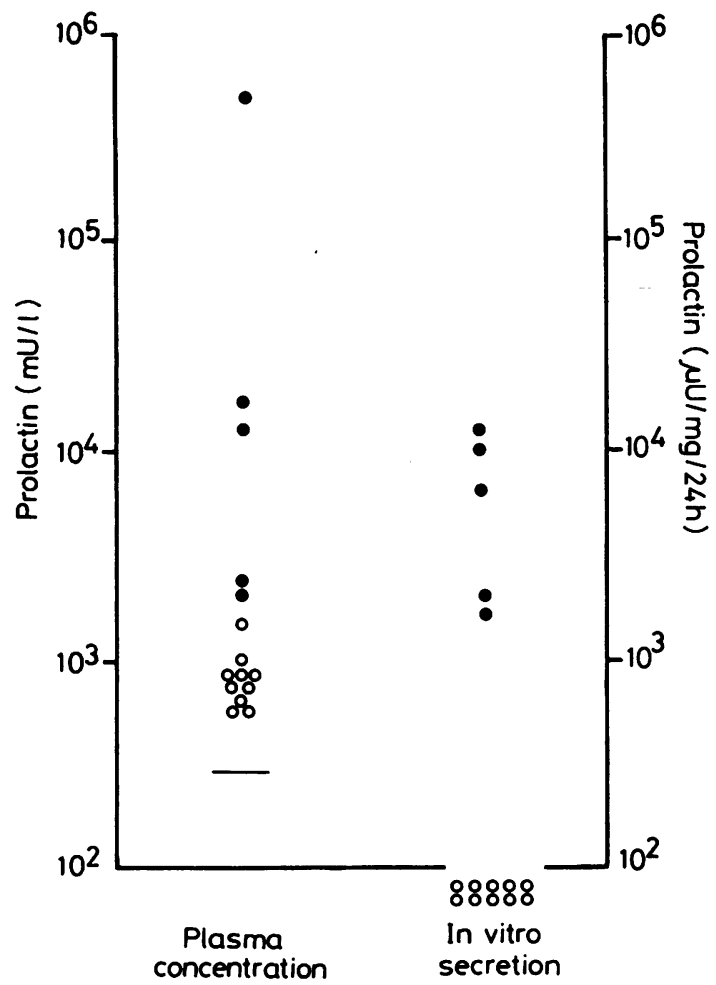

Fig 1 Plasma levels and IN VITRO secretion of prolactin in 15 patients with hyperprolactinaemia (log scales). High secretion rates (closed circles) correspond to patients with plasma prolactin of $>2000 \mathrm{mU} / \mathrm{l}$. See text for details of secretion rates $<100 \mu U / \mathrm{mg} / 24 \mathrm{~h}$.
Between assay coefficient of variance for $\mathrm{LH}$ was $10 \cdot 1 \%$ and for FSH $8.2 \%$. Normal plasma values for prolactin, $\mathrm{LH}$ and FSH are shown in the table.

NSE was assayed by double-antibody radioimmunoassay using a kit kindly donated by Pharmacia Ltd. The NSE used as standard and tracer was purified from human brain by the method of Pählman et al. ${ }^{15}$ All samples in this study were run in the same assay. The detection limit was $6.5 \mathrm{ug} / \mathrm{l}$ and intra-assay error was $<5 \%$.

\section{Results}

\section{Prolactin secretion}

Fifteen patients were hyperprolactinaemic at the time of surgery but only five tumours showed high rates of prolactin secretion in vitro. Figure 1 shows the plasma prolactin levels and in vitro secretion rates in these 15 patients. In the five patients whose plasma prolactin ranged from $2,240-517,000 \mathrm{mU} / 1$ the in vitro secretion rate ranged from $1,785-13,447 \mu \mathrm{U} / \mathrm{mg} / 24 \mathrm{~h}$. Four of these tumours were regarded as true prolactinomas and the fifth (Patient 10) as a mixed tumour. Preoperative plasma prolactin was normal in two patients on bromocriptine (Patients 5 and 11) and in vitro prolactin secretion remained almost completely suppressed at $45 \mu \mathrm{U} / \mathrm{mg} / 24 \mathrm{~h}$ and $175 \mu \mathrm{U} / \mathrm{mg} / 24 \mathrm{~h}$. Plasma prolactin levels of $>5,000 \mathrm{mU} / 1$ and 44,000 $\mathrm{mU} / 1$ prior to bromocriptine suggest that these tumours were prolactin secreting and they are shown as a prolactinoma and a mixed tumour respectively in the table. In the 10 patients whose plasma prolactin ranged from $615-1650 \mathrm{mU} / 1$ in vitro prolactin secretion was undetectable in eight and negligible in two (33.9 and $28.9 \mu \mathrm{U} / \mathrm{mg} / 24 \mathrm{~h}$ ). These tumours were regarded as "functionless". Plasma prolactin was normal in three patients with "functionless" tumours and in vitro secretion rates were $<5 \mu \mathrm{U} / \mathrm{mg} / 24 \mathrm{~h}$.

\section{GH secretion}

Tumours from patients with acromegaly secreted the expected large quantities of $\mathrm{GH}$ in vitro (fig. 2). In five untreated patients the secretion rate ranged from $1,665-28,344 \mu \mathrm{U} / \mathrm{mg} / 24 \mathrm{~h}$. Patient 11 had persistently raised plasma GH levels on bromocriptine and an in vitro secretion rate of $2,324 \mu \mathrm{U} / \mathrm{mg} / 24 \mathrm{~h}$.

Very low or undetectable GH secretion by five prolactinomas and 11 "functionless" tumours indicated that contamination of tumour tissue by normal pituitary was absent or minimal. Values ranged from undetectable to $3 \cdot 1 \mu \mathrm{U} / \mathrm{mg} / 24 \mathrm{~h}$ in 13 cases and were $7 \cdot 0,19 \cdot 2$ and $28 \cdot 0 \mu \mathrm{U} / \mathrm{mg} / 24 \mathrm{~h}$ in three.

\section{LH and FSH secretion}

In vitro secretion rates for $\mathrm{LH}$ and $\mathrm{FSH}$ are shown in fig 3. Secretion of both hormones by functionless tumours as a group was significantly increased compared with endocrine-active tumours $(p=<0.01$, 


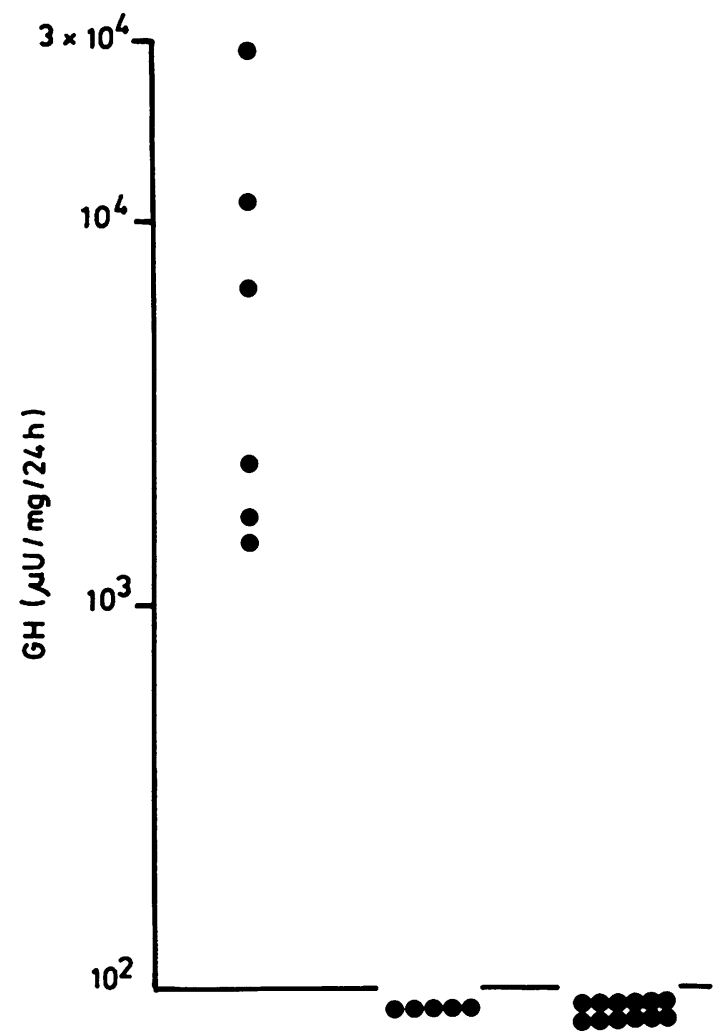

Acromegaly Prolactinoma Functionless

Fig 2 Growth hormone secretion IN VITRO by 22 tumours (log scale). See text for details of secretion rates $<100 \mu \mathrm{U} / \mathrm{mg} / 24 \mathrm{~h}$.

Mann-Whitney $U$ test). There was no significant difference in the secretion rate of LH or FSH between prolactin and growth hormone secreting tumours. Low levels of LH secretion by endocrine-active tumours ranged from $0 \cdot 1-1 \cdot 1 \mathrm{mIU} / \mathrm{mg} / 24 \mathrm{~h}$. The secretion rate of LH by "functionless" tumours fell within this range in only three cases and was increased in 10. FSH secretion by five endocrine-active tumours was undetectable and ranged from 0.1-1.8 $\mathrm{mIU} / \mathrm{mg} / 24 \mathrm{~h}$ in six. The secretion rate by "functionless" tumours fell within this range in only six cases and was increased in seven. LH secretion was high in all 7 tumours showing high FSH secretion.

In spite of high gonadotrophin secretion in vitro plasma levels of $\mathrm{LH}$ were raised in only one patient and of FSH in only four, all of whom were male.

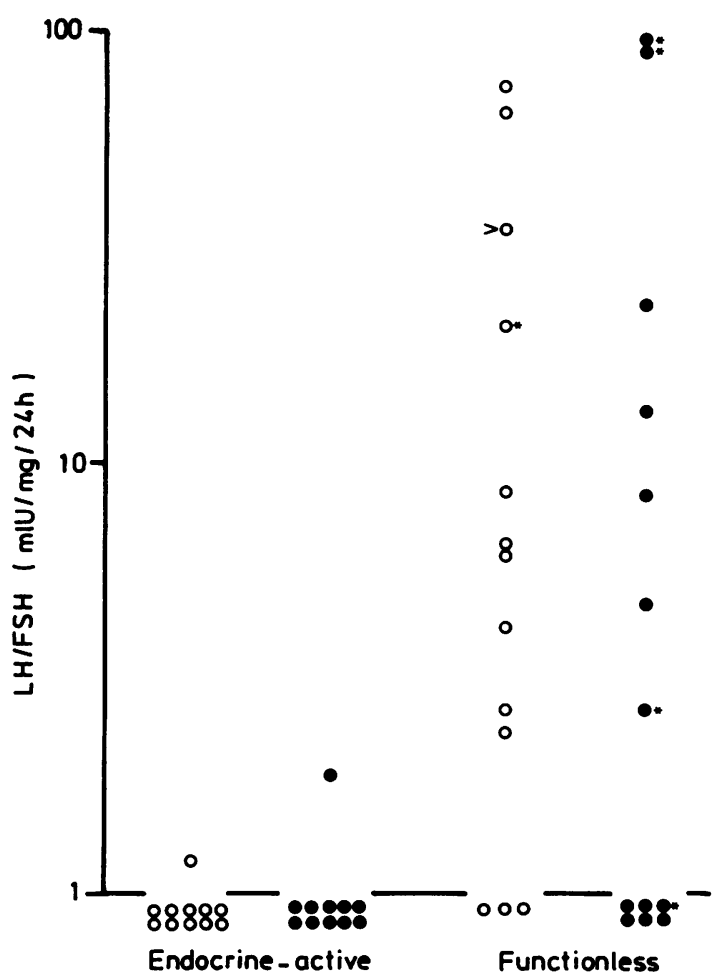

Fig 3 LH (open circles) and FSH (closed circles) secretion in vitro by 24 tumours (log scale). Starred circles correspond to high plasma $\mathrm{LH}$ and FSH levels. See text for details of secretion rates $<1-0 \mathrm{mIU} / \mathrm{mg} / 24 \mathrm{~h}$.

\section{NSE secretion}

Secretion rates for NSE are shown in fig 4. "Functionless" tumours as a group showed a significant increase in NSE secretion compared with endocrineactive tumours ( $\mathrm{p}=<0.01$, Mann-Whitney $U$ test). NSE secretion by two prolactinomas and three GH secreting tumours was undetectable and ranged from $0.5-2.8 \mathrm{ng} / \mathrm{mg} / 24 \mathrm{~h}$ in the remaining six. Only four "functionless" tumours secreted NSE at these low levels, the values ranging from $4.4->200 \mathrm{ng} / \mathrm{mg} / 24 \mathrm{~h}$ in the remaining nine. There was no correlation between the secretion rate of NSE and LH or FSH (p > 0.5, Wilcoxon's $t$ test).

\section{Discussion}

This study has shown that a majority of "functionless" tumours in an unselected series were associated with hyperprolactinaemia in vivo and increased secretion of gonadotrophins and NSE in vitro com- 


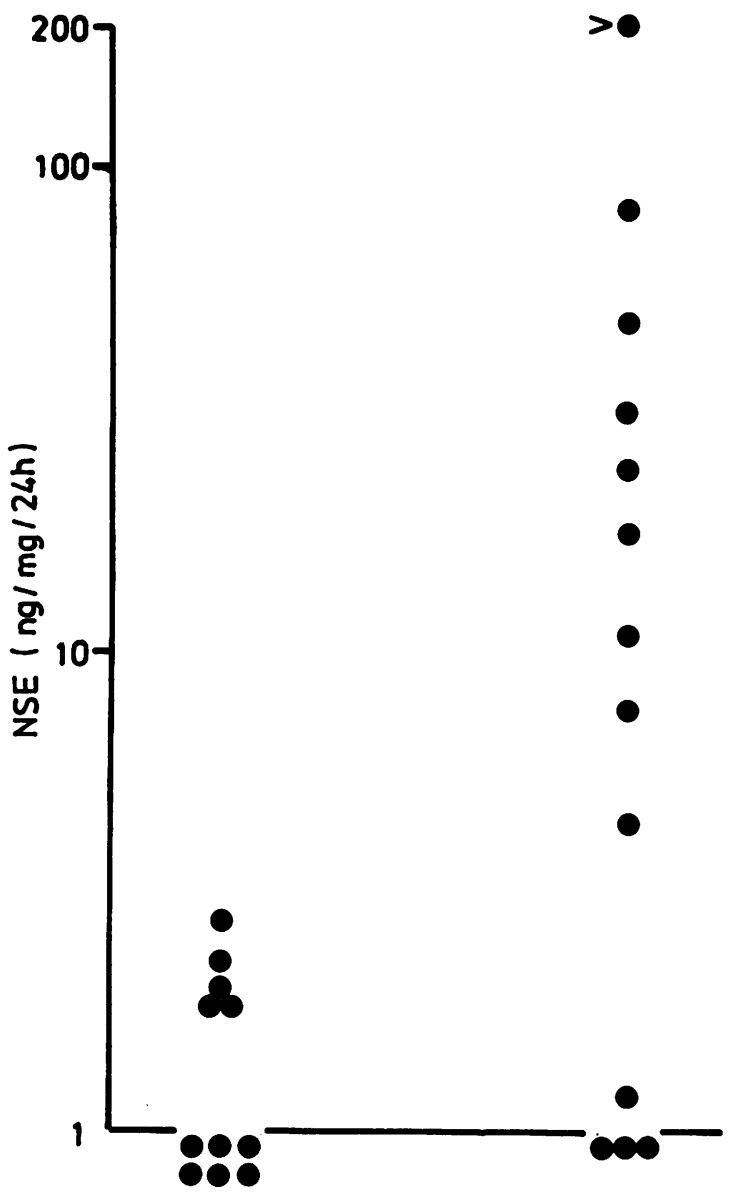

Endocrine-active

Fig 4 NSE secretion in vitro by 24 tumours (log scale). See text for details of secretion rates $<n g / m g / 24 h$.

pared with prolactin and growth hormone secreting tumours.

The failure of 10 tumours from hyperprolactinaemic patients to secrete prolactin in vitro confirms the need to distinguish true prolactinomas from "functionless" tumours. Hyperprolactinaemia in patients with "functionless" tumours is probably due to a loss of the normal inhibitory control of prolactin secretion by hypothalamic dopamine acting as a physiological prolactin inhibiting factor (PIF). Several authors have reported hyperprolactinaemia due to craniopharyngiomas and other suprasellar lesions ${ }^{16-18}$ which cause increased prolactin secretion presumably by interfering with the delivery of PIF to the pituitary. Lundberg et $a l^{18}$ and Nabarro ${ }^{16}$

predicted that pituitary tumours other than prolactinomas could cause hyperprolactinaemia by the same mechanism. Recent reports of negative immunoperoxidase staining for prolactin in tumours from patients with modest hyperprolactinaemia have shown that "functionless" tumours may indeed masquerade as prolactinomas and can be regarded as "pseudoprolactinomas". ${ }^{19}$ The precise level of plasma prolactin required to confidently diagnose a true prolactinoma is not clear and it is probable that a degree of overlap exists between hyperprolactinaemia due to a prolactinoma and hyperprolactinaemia due to stalk compression.

Direct measurement of the prolactin secretion rate in vitro is likely to be more accurate in making this distinction than the qualitative assessment given by immunoperoxidase staining. In the present study two tumours from patients with prolactin levels of 2,240 $\mathrm{mU} / 1$ and $2,600 \mathrm{mU} / 1$ were clearly true prolactinomas in vitro, whereas prolactin secretion was absent or negligible if plasma prolactin was $<1,650 \mathrm{mU} / \mathrm{l}$. It may be concluded that a patient with a pituitary macroadenoma and a plasma prolactin of $<2000 \mathrm{mU} / 1$ is most unlikely to have a true prolactinoma. The distinction between prolactinomas and pseudoprolactinomas is clinically important because "functionless" tumours rarely regress on treatment with bromocriptine, ${ }^{20}$ even though prolactin levels are suppressed. A combination of tissue culture and immunoperoxidase staining would provide the most accurate diagnosis of true prolactinomas and predict which tumours are likely to respond to bromocriptine following an incomplete surgical removal.

Our finding of increased FSH and/or LH by 10 of 13 "functionless" tumours supports the view of Mashiter et al $^{13}$ that gonadotrophin secretion by these tumours is more common than previously supposed. Secretion of the $\alpha$ subunit of glycoprotein hormones by "functionless" tumours ${ }^{21}$ is well recognised but is not specific in that growth hormone and prolactin secreting tumours also secrete $\alpha$ subunit. ${ }^{22}$ We have shown that the secretion of whole immunoreactive LH and FSH on the other hand is significantly greater by "functionless" tumours than by endocrine-active tumours. It seems unlikely therefore that LH or FSH in the tissue culture supernatant is derived from islands of normal gonadotrophs which have become engulfed by tumour tissue. Nor is it likely that the immunoreactive LH and FSH assayed in this study can be explained by cross-reactivity of the antisera with $\alpha$ subunit since cross-reaction with $\alpha$ HCG is $<0 \cdot 1$ for both antisera.

There are, however, reasons to doubt that $\mathrm{LH}$ and FSH are the major hormones secreted by "functionless" tumours. Firstly, in agreement with Mashiter $e t a l,{ }^{13}$ we noted that the secretion rates of $\mathrm{LH}$ and 
FSH were much lower than the rates for prolactin and growth hormone secretion by endocrine-active tumours. In addition, Trouillas et al ${ }^{11}$ reported that the amounts of LH and FSH which could be extracted from tumours in their series were lower than the amounts of LH and FSH extracted from normal pituitary. Secondly, immunoperoxidase staining has shown that only a minority of tumour cells contain FSH or LH. ${ }^{13}$ Thirdly, the expected increase in plasma LH or FSH was uncommon in our patients and often marginal when present. This was particularly true of $\mathrm{LH}, 10$ tumours secreting an excess in vitro but only one patient showing a raised plasma LH. In the case of FSH there was no clear correlation between high secretion rates in vitro and raised plasma levels (fig 3). Preoperative plasma levels of $\mathrm{LH}$ and FSH were available for only one patient in the study by Mashiter et al. ${ }^{13}$ Although secretion of immunoreactive LH and FSH by "functionless" tumours undoubtedly occurs we are therefore reluctant to regard these tumours as "gonadotrophinomas." Indeed only one patient in this series (Patient 24) may have harboured a true FSH secreting tumour in view of the recognised association with hypogonadism ${ }^{23}$ and the clear cut increase in plasma FSH with an exaggerated FSH response to the releasing hormone.

The significance of NSE in neuroendocrine cells is unknown but the high level of NSE secretion by nine "functionless" tumours provides biochemical evidence for their metabolic activity. Although NSE is uniformly present in endocrine-active tumours by immunocytochemical staining, ${ }^{8}$ low or undetectable levels of NSE secretion by the endocrine-active tumours in this study suggest that prolactin and GH secreting cells are not a major source of NSE. The lack of correlation between NSE and LH or FSH secretion does not support the view that gonadotrophs are the major source of NSE in "functionless" tumours. We have also measured NSE secretion by two tumours from patients with Cushing's syndrome. The results were not included in this series because ACTH levels were not measured, but NSE secretion was low in both cases. NSE secretion by "functionless" tumours was not universally increased since the values in four tumours were comparable to those of endocrineactive tumours. Present evidence suggests however that a high rate of NSE secretion is characteristic of the cell type from which most "functionless" tumours derive.

Our preliminary studies of plasma NSE levels show occasional high values in patients with pituitary tumours but it is unlikely that plasma NSE can be used to monitor therapy in "functionless" tumours. Nevertheless, measurement of NSE secretion in vitro should provide a useful biochemical marker in further studies of these tumours whose putative hormonal activity remains an enigma.

We are grateful to Dr PJ Wood for LH and FSH assays.

\section{References}

${ }^{1}$ Kovaks K, Horvath E, Ryan N, Ezrin C. Null cell adenoma of the human pituitary. Virchow's Arch Pathol Anat 1980;387:165-74.

${ }^{2}$ Schmechel D, Marangos PJ, Brightman M, Goodwin FK. Brain enolases as specific markers of neuronal and glial cells. Science 1978;199:313-5.

${ }^{3}$ Facer P, Polak JM, Marangos PJ, Pearse AGE. Immunological localization of neurone-specific enolase (NSE) in the gastrointestinal tract. Proc R Microscop Soc 1980;15:113-4.

${ }^{4}$ Schmechel D, Marangos PJ, Brightman M. Neuronespecific enolase is a molecular marker for peripheral and central neuroendocrine cells. Nature 1978;276:834-6.

${ }^{5}$ Cole GA, Polak JM, Wharton J, Marangos P, Pearse AGE. Neurone-specific enolase as a useful histochemical marker for the neuroendocrine system of the lung. J Pathol 1980;132:351-2.

${ }^{6}$ Tapia FJ, Polak JM, Barbosa AJA, et al. Neurone-specific enolase is produced by neuroendocrine tumours. Lancet 1981;1:808-11.

${ }^{7}$ Marangos PJ, Schmechel D, Parma AM, Clarke RL, Goodwin FK. Measurement of neurone-specific (NSE) and non-neuronal (NNE) isoenzymes of enolase in rat, monkey and human nervous tissue. $J$ Neurochim 1979;33:319-29.

${ }^{8}$ Van Noorden S, Polak JM, Robinson M, Pearse AGE, Marangos PJ. Neuron-specific enolase in the pituitary gland. Neuroendocrinology 1984;38:309-16.

${ }^{9}$ Royds JA, Timperley WR, Taylor CB. Levels of enolase and other enzymes in the cerebrospinal fluid as indices of pathological change. J Neurol Neurosurg Psychiatry 1981;44:1129-35.

${ }^{10}$ Royds JA, Davies-Jones GAB, Lewtas NA, Timperley WR, Taylor CB. Enolase isoenzymes in the cerebrospinal fluid of patients with diseases of the nervous system. J Neurol Neurosurg Psychiatry 1983;46:1031-6.

${ }^{11}$ Trouillas J, Girod C, Sassolas G, et al. Human pituitary gonadotropic adenoma; histological, immunocytochemical and ultrastructural and hormonal studies in eight cases. J Pathol 1981;135:315-36.

${ }^{12}$ Kovaks K. Light and electron microscopic pathology of pituitary tumours: immunohistochemistry. In: Black PM, Zervas NT, Ridgeway EC, Martin JB, eds. Secretory Tumours of the Pituitary Gland. Progress in endocrine research and therapy, vol. 1. New York. Raven Press 1984:365-75.

${ }^{13}$ Mashiter K, Adams E, Van Noorden S. Secretion of LH, FSH and PRL shown by cell culture and immunocytochemistry of human functionless pituitary adenomas. Clin Endocrinol 1981;15:103-12. 
${ }^{14}$ Lawton NF, Evans AJ, Weller RO. Dopaminergic inhibition of growth hormone and prolactin release during continuous in vitro perifusion of normal and adenomatous human pituitary. J Neurol Sci 1981; 49:229-39.

${ }^{15}$ Pählman S, Esscher T, Bergvall P, Odelstad L. Purification and characterization of human neuronespecific enolase: development of a radioimmunoassay. Tumour Biol, In press.

${ }^{16}$ Nabarro JDN. Pituitary prolactinomas. Clin Endocrinol 1982;17:129-55.

${ }^{17}$ Kappala LP, Molitch ME, Post KD, et al. Galactorrhoea, oligo/amenorrhoea and hyperprolactinaemia in patients with craniopharyngiomas. $J$ Clin Endocrinol Metab 1980;51:798-800.

${ }^{18}$ Lundberg PO, Osterman PO, Wide L. Serum prolactin in patients with hypothalamic and pituitary disorders. $J$ Neurosurg 1981;55:194-9.
${ }^{19}$ Grossman A, Besser GM. Prolactinomas. Br Med J 1985;1:182-4.

${ }^{20}$ Barrow DL, Tindall GT, Kovaks K, Thorner MO, Horvath E, Hoffman JC. Clinical and pathological effects of bromocriptine on prolactin-secreting and other pituitary tumours. J Neurosurg 1984;60:1-7.

${ }^{21}$ Kourides IA, Weintraub BD, Rosen SW, Ridgeway EC, Kliman B, Maloof F. Secretion of alpha subunit of glycoprotein hormones by pituitary adenomas. J Clin Endocrinol Metab 1976;43:97-106.

${ }^{22}$ MacFarlane IA, Beardwell CG, Shalet SM, Darbyshire PJ, Hayward E, Sutton ML. Glycoprotein hormone alpha subunit secretion by pituitary adenomas: Influence of external irradiation. Clin Endocrinol 1980;13:215-22.

${ }^{23}$ Woolf PD, Schenk EA. An FSH producing tumour in a patient with hypogonadism. J Clin Endocrinol Metab 1974;38:561-8. 